\title{
The association between tobacco smoke exposure and vitamin D levels among US general population, 2001-2014: temporal variation and inequalities in population susceptibility
}

\author{
Lei Yuan ${ }^{1}$ (D) . Jingyi $\mathrm{Ni}^{1}$
}

Received: 1 August 2021 / Accepted: 29 November 2021 / Published online: 12 January 2022

(c) The Author(s), under exclusive licence to Springer-Verlag GmbH Germany, part of Springer Nature 2022

\begin{abstract}
Tobacco smoking is endocrine-disrupting and may interfere with vitamin D endocrine systems (VDES), but supporting evidence is limited and inconsistent. Also, there is a lack of evidence on whether the association between tobacco smoke exposure and VD levels exhibit temporal variation. Data from the National Health and Nutrition Examination Survey was used to evaluate the association between tobacco smoke exposure and VD levels among US general participants from 2001 to 2014. We examined the linear association between serum cotinine and 25(OH)D concentrations, as well as relationship between tobacco smoke exposure categories (active, passive, non-smoking) with VD status (deficiency, inadequacy, sufficiency, intoxication), and assessed whether specific gender, age (3-11, 12-19, 20-59, $\geq 60$ years), ethnicity/race, or body mass index (BMI) groups were disproportionately impacted. During 2001-2004, a decrease in both serum cotinine and passive smoking prevalence was observed, with a stabilized active smoking rate. The estimates for the association between tobacco smoke exposure and suboptimal VD levels increased over the study period. Overall results indicated that serum cotinine was negatively associated with $25(\mathrm{OH}) \mathrm{D}$ in all participants. Tobacco smoke exposure, including both active and passive smoking exposure, was associated with increased risk of VD deficiency. Moreover, active smoking was additionally related to enhanced risk of VD inadequacy. These associations showed some age and gender differences, with consistent and stronger associations observed in female adults. In contrast, effects of tobacco smoke exposure on VD levels were mostly negative or non-significant among children and adolescents aged 3-19 years. The percentage of US general population with active smoking exposure stabilized over the 14-year period and was still high. Tobacco smoke exposure may disrupt vitamin D levels with an increasing temporal trend in the risk. Our results also provided initial evidence of smoking exposure on VD intoxication, which needs to be further verified. Convincing studies have linked tobacco use exposure, to dysfunctional VDES accompanied with declined serum levels of VD metabolites. However, evidence on the association between tobacco smoke exposure and VD status was rather limited and inconsistent, and there were no researches to date that estimated the temporal variation of the association as well as the effects of smoke exposure on VD intoxication. This study analyzed national survey data, to evaluate the temporal trends in effects of tobacco smoke exposure on VD levels over a decade, and to comprehensively assess the impacts of tobacco smoke exposure on VD levels across specific subgroups. The evidence suggests that the prevalence of active smoking exposure stabilized over the 14-year period and was still high. Moreover, tobacco smoke exposure may disrupt vitamin D levels among general population, with an increasing temporal trend and age-, gender-differences in risk.
\end{abstract}

Keywords Tobacco smoke $\cdot$ Cotinine $\cdot$ Vitamin D $\cdot$ Vitamin D deficiency $\cdot$ NHANES

Responsible Editor: Lotfi Aleya

Lei Yuan and Jingyi Ni contributed equally to this work.

Lei Yuan

leiy@tongji.edu.cn

Extended author information available on the last page of the article

\section{Introduction}

Evidence has affirmed the carcinogen, neurotoxic, and endocrine-disrupting roles of tobacco use exposure, including both active and passive smoking exposure, in the pathogenesis of a wide range of diseases (Mousavi et al. 2019). The principle component of tobacco products is nicotine. 
The absorption of nicotine by human body from tobacco is mainly through inhalation via smoke and vaporization exposure; its other routes include oral mucosa absorption via chewing and sniffing, and also through skin absorption (Benowitz et al. 2009b). Once entering into the body, nicotine is absorbed immediately and rapidly reaches the bloodstream and the brain, leading to an extensive distribution to body tissues. About $70-80 \%$ of nicotine is metabolized into cotinine in humans (Benowitz and Jacob 1994).

Although substantial decline in smoking rates is expected through efforts in public consciousness, education, and public policy since 1964 in the USA (National Institute on Drug Abuse, 2020), studies have consistently indicated that the tobacco smoke exposure in the US general population is still high. For example, data accessed from the National Health and Nutrition Examination Survey (NHANES) for 1999-2004 revealed that 9\% of adolescents aged 12-19 years and 30\% of US adults aged 20 years or older were active smokers according to their serum cotinine values (Benowitz 2009a). Furthermore, it is worth noticing that smoking has become increasingly appealing to both smokers and non-smokers due to the emergence of electronic cigarettes (e-cigarettes) in the US market since 2007, together with increased flavor choices for both traditional and electronic cigarettes. Accordingly, the NHANES 2009-2010 data analysis showed that about $42 \%$ of the US children and adolescents of 3-17 years had serum cotinine concentrations reaching the secondhand smoke exposure levels, with $9 \%$ of the teenagers aged 13-17 years reaching the range of active smoking (Nwosu and Kum-Nji 2018; Chatham-Stephens (2014).

Vitamin D (VD) is a fat-soluble hormone and is well known for functions in maintaining bone health and skin barrier. Its nutrigenomic and epigenetic functions have also been demonstrated through links between VD insufficiency or deficiency with various diseases, including tumorigenesis metastasis (Mahamat-Saleh et al. 2020), autoimmune diseases (Sharief et al. 2011; Ahmed Mohamed et al. 2021), cardiometabolic disorders (Marquina et al. 2019; Pott-Junior et al. 2020), and even worse, coronavirus disease 2019 (COVID-19) risk and severity (Mitchell 2020; Pereira et al. 2020). Potential evidence also indicates that VD intoxication induces calcium and phosphorus dysregulation, causing damage to tissues and organs (Razzaque 2018). Although VD level was thought to be closely related to sun exposure and dietary intake, a few epidemiological studies have indicated the endocrine-disrupting role of tobacco smoke exposure, and linked it to dysfunctional Vitamin D endocrine systems (VDES) accompanied with declined serum levels of VD metabolites (Brot et al. 1999; Banihosseini et al. 2013; Manavi et al. 2015; Byun et al. 2017; Nwosu and Kum-Nji 2018). By estimating smoking status and VD levels among 510 healthy perimenopausal women aged $45-58$ years,
Brot et al. (1999) reported that female smokers had significantly decreased levels of serum VD. A previous NHANES 2009-2010 analysis found that tobacco smoke exposure among 2263 US children (3-17 years) was independently associated with VD deficiency (Nwosu and Kum-Nji 2018). The NHANES 2001-2006 illustrated that serum cotinine of adults (18-70 years) was associated with lower VD concentration, with results varied by gender and ethnicity/race (Manavi et al. 2015). Contrastingly, a cohort study enrolling 54 mother-infant pairs in Iran concluded that maternal exposure to cigarette smoking during pregnancy showed insignificant influence on serum VD levels in mothers (Banihosseini et al. 2013). Moreover, a national cross-sectional study based on 2515 Korean adolescents aged 10-18 years during 2008-2011 also suggested no evidence of the relationship between cotinine-verified smoking and VD deficiency (Byun et al. 2017). However, the effects of tobacco smoke exposure on VD intoxication have not, to our knowledge, been evaluated. Also, because the emissions of tobacco have changed with different devices over time (Martuzevicius et al. 2019), the health impacts of tobacco smoke exposure might also display temporal variation. Nevertheless, few studies of tobacco smoke and VD levels have examined the temporal change in the association over time using a long-term analysis.

Thus, the association between tobacco smoke exposure and VD status are not consistent among previous human studies, the temporal trend and the complicated demographic characteristics that influence the relationship have not been sufficiently examined. More comprehensive investigations covering a broader range of people at extended period over time are needed. Therefore, this study was aimed to use NHANES data over the entire 14-year period (2001-2014) (1) to evaluate the associations between tobacco smoke and VD status, and to examine whether the relations were consistent or not among different cycles; (2) to estimate various demographic factors that influence the smoke-VD association, and to help discern the vulnerable subpopulations on which the public health interventions should be focused.

\section{Methods}

\section{Study population}

The National Health and Nutrition Examination Survey, or NHANES, is a nationally ongoing health survey conducted by the Centers for Disease Control and Prevention (CDC)/ National Center for Health Statistics (NCHS) since 1959 to monitor the health and nutritional status of the noninstitutionalized US residents (https://www.cdc.gov/nchs/ nhanes). Representative participants of all ages were randomly selected through a statistical process using US census information, and were then personally contacted for a home 
interview concerning sociodemographic characteristics, health history, and behavior. Meanwhile, a one-time specific health examination was completed based on their age, gender, and medication conditions, where biological samples were collected. The NCHS Research Ethics Review Board (ERB) approval and documented consent was obtained from all participants. NHANES released its data for public use in each 2 -year cycle. Currently, serum cotinine was only available among participants aged $\geq 3$ years; thus, we included a total of 49,338 participants aged $\geq 3$ years who had available data on serum cotinine, vitamin $\mathrm{D}$, and sociodemographic covariates (listed below) from seven surveys cycles (2001-2014) in the analysis.

\section{Measurement of tobacco smoke exposure}

Tobacco use smoke exposure for NHANES was assessed through the measurement of serum cotinine, a major metabolite of nicotine. Cotinine has been used as a highly specific and sensitive biomarker in quantifying short-term exposure of tobacco use due to its relatively long half-life (15-20 h; nicotine: $2 \mathrm{~h}$ ), and wide detection in biological fluids, including blood, urine, saliva, hair, and nails (Benowitz 1996; Benowitz et al. 2009b; Akinkugbe et al. 2019).

In each survey cycle, about $90 \%$ of eligible participants (aged 3 years and older) had cotinine examined in serum in NHANES 2001-2014. Serum cotinine was measured by an isotope-dilution high-performance liquid chromatography/atmospheric pressure chemical ionization tandem mass spectrometry (ID HPLC-APCI MS/MS) method. Detailed analytical methodology was available at NHANES website (https://wwwn.cdc.gov/Nchs/Nhanes/2013-2014/ COT_H.htm). The lower limit of detection (LLOD in ng/ $\mathrm{mL}$ ) for serum cotinine in each 2-year cycle from 2001 to 2014 was $0.015 \mathrm{ng} / \mathrm{mL}$. The results below the LLODs were replaced with the LLODs divided by the square root of two $(\mathrm{LLOD} / \sqrt{ } 2)$. The detection rates of cotinine are summarized in Table 1 .

According to CDC, nonsmokers exposed to typical levels of passive/secondhand smoke (SHS) have serum cotinine levels of less than $1 \mathrm{ng} / \mathrm{mL}$, with heavy exposure to SHS producing levels in the $1-10 \mathrm{ng} / \mathrm{mL}$ range. Active smokers are defined as levels higher than $10 \mathrm{ng} / \mathrm{mL}$ (https://www.cdc. gov/biomonitoring/Cotinine_BiomonitoringSummary.html).

\section{Measurement of vitamin D}

Serum 25-hydroxyvitamin D $(25(\mathrm{OH}) \mathrm{D})$ is the predominant circulating form of vitamin $\mathrm{D}$, and is deemed as the most reliable index of vitamin D status. For NHANES 2001-2006, serum 25(OH)D concentrations were measured using the DiaSorin RIA kit. Due to observed method variation of DiaSorin assay, the CDC applied an ultra-high performance liquid chromatography-tandem mass spectrometry (UHPLC-MS/MS) method to detect 25(OH)D in serum for NHANES 2007-2014, and predicted LC-MS/MS equivalent quantity for NHANES 2001-2006. The detailed detecting methods and standardization were shown at the official site (https://wwwn.cdc.gov/nchs/nhanes/vitamind/ analyticalnote.aspx?h=/Nchs/Nhanes/2003-2004/VID_C. htm\&t=VID_C\%20Doc).

US Food and Nutrition Board (FNB) at the National Academies of Sciences, Engineering, and Medicine (NASEM) defined the vitamin D status as: deficiency at serum 25(OH)D concentrations less than $30 \mathrm{nmol} / \mathrm{L}$ (12 ng/ $\mathrm{mL})$, inadequacy at 30 to $50 \mathrm{nmol} / \mathrm{L}(12-20 \mathrm{ng} / \mathrm{mL})$, and sufficiency for bone and overall health at levels of $50 \mathrm{nmol} / \mathrm{L}$ $(20 \mathrm{ng} / \mathrm{mL})$ or more. We also defined the VD intoxication as $25(\mathrm{OH}) \mathrm{D}$ concentrations greater than $125 \mathrm{nmol} / \mathrm{L}$ ( $50 \mathrm{ng} /$ $\mathrm{mL}$ ) according to the FNB committee (https://ods.od.nih. gov/factsheets/VitaminD-HealthProfessional/).

\section{Sociodemographic and lifestyle factors}

Potential confounding factors were considered according to previous researches (Juonala et al. 2019; Luo et al. 2020), including gender, age, ethnicity/race, ratio of family income to poverty (PIR), body mass index (BMI), tobacco products use, dietary vitamin D intakes, alcohol use, physical activity, kidney health, and NHANES cycle. Specifically, PIR represents the social economic status of the family (or individual), and is a ratio of family income to poverty guidelines specific to the survey year, family size, and geographic location. Of note, weight status categories for participants aged 3-19 years old was defined as four levels: underweight (BMI $<5$ th percentile), normal weight $(5$ th $\leq$ BMI $<85$ th percentile), overweight ( 85 th $\leq \mathrm{BMI}<95$ th percentile), and obese (BMI $\geq 95$ th percentile); for adults aged 20 years old and older, standard weight status categories associated with BMI ranges were underweight $\left(<18.5 \mathrm{~kg} / \mathrm{m}^{2}\right)$, normal weight $\left(18.5-24.9 \mathrm{~kg} / \mathrm{m}^{2}\right)$, overweight $\left(25-29.9 \mathrm{~kg} / \mathrm{m}^{2}\right)$, and obese $\left(\geq 30 \mathrm{~kg} / \mathrm{m}^{2}\right)$. Given that there were few cases $(1.7 \%)$ in the underweight category, we combined underweight and normal weight into one class in the regression analyses. In addition to the quantitative assessment of serum cotinine, questions regarding recent tobacco products use during the past 5 days were answered by eligible participants aged 12 years and older. From 2013-2014 survey cycle, e-cigarettes were also included as another form of tobacco. Specifically, participants were asked, "During the past 5 days, including today, did you smoke cigarettes, pipes, cigars, little cigars or cigarillos, water pipe, hookahs, or e-cigarettes?" Information on alcohol use was collected using question "Had at least 12 alcohol drinks per year?" (available from all participants aged 20 years and older in NHANES 2001-2010, aged 18 years and older in 
Table 1 Population characteristics with serum cotinine and VD levels by survey cycle in NHANES 2001-2014

\begin{tabular}{|c|c|c|c|c|c|c|c|c|}
\hline & $\begin{array}{l}\text { Overall } \\
(N=49,338)\end{array}$ & $\begin{array}{l}\text { 2001-2002 } \\
(N=7017)\end{array}$ & $\begin{array}{l}\text { 2003-2004 } \\
(N=7291)\end{array}$ & $\begin{array}{l}\text { 2005-2006 } \\
(N=7343)\end{array}$ & $\begin{array}{l}\mathbf{2 0 0 7 - 2 0 0 8} \\
(N=6160)\end{array}$ & $\begin{array}{l}\text { 2009-2010 } \\
(N=7434)\end{array}$ & $\begin{array}{l}\text { 2011-2012 } \\
(N=6726)\end{array}$ & $\begin{array}{l}\text { 2013-2014 } \\
(N=7367)\end{array}$ \\
\hline Age (year, mean (SD)) & $35.2(23.1)$ & $33.5(22.1)$ & $33.7(23.7)$ & $32.6(22.5)$ & $38.0(23.8)$ & $37.4(23.2)$ & $35.7(22.9)$ & $36.2(23.1)$ \\
\hline \multicolumn{9}{|l|}{ Age (\%) } \\
\hline $3-11$ & 8355 (16.9) & $925(13.2)$ & $1213(16.6)$ & $1245(17.0)$ & $1111(18.0)$ & $1245(16.7)$ & $1263(18.8)$ & $1353(18.4)$ \\
\hline $12-19$ & $9857(20.0)$ & $1995(28.4)$ & $1934(26.5)$ & $1880(25.6)$ & $863(14.0)$ & $1065(14.3)$ & $989(14.7)$ & $1131(15.4)$ \\
\hline $20-59$ & $21,012(42.6)$ & $2857(40.7)$ & $2640(36.2)$ & $2942(40.1)$ & $2659(43.2)$ & $3464(46.6)$ & $3111(46.3)$ & $3339(45.3)$ \\
\hline$>=60$ & $10,114(20.5)$ & $1240(17.7)$ & $1504(20.6)$ & $1276(17.4)$ & $1527(24.8)$ & $1660(22.3)$ & $1363(20.3)$ & $1544(21.0)$ \\
\hline \multicolumn{9}{|l|}{ Ethnicity/Race $(n, \%)$} \\
\hline Hispanic & $13,880(28.1)$ & 2085 (29.7) & $2034(27.9)$ & $2076(28.3)$ & $1922(31.2)$ & $2297(30.9)$ & $1598(23.8)$ & $1868(25.4)$ \\
\hline Non-Hispanic Black & $11,434(23.2)$ & $1616(23.0)$ & $1908(26.2)$ & $1934(26.3)$ & $1264(20.5)$ & $1348(18.1)$ & $1793(26.7)$ & $1571(21.3)$ \\
\hline Non-Hispanic White & $20,257(41.1)$ & 3067 (43.7) & $3039(41.7)$ & $2983(40.6)$ & $2718(44.1)$ & $3352(45.1)$ & $2256(33.5)$ & $2842(38.6)$ \\
\hline Other race & $3767(7.64)$ & $249(3.55)$ & $310(4.25)$ & $350(4.77)$ & $256(4.16)$ & $437(5.88)$ & $1079(16.0)$ & $1086(14.7)$ \\
\hline BMI $\left(\mathrm{kg} / \mathrm{m}^{2}\right.$, mean $\left.(\mathrm{SD})\right)$ & $26.1(7.40)$ & $25.6(6.74)$ & $25.5(6.95)$ & $25.9(7.44)$ & $26.4(7.44)$ & $26.6(7.60)$ & $26.2(7.62)$ & $26.4(7.87)$ \\
\hline \multicolumn{9}{|l|}{ BMI category $(n, \%)$} \\
\hline Normal & $19,012(38.5)$ & $2910(41.5)$ & $2990(41.0)$ & $2949(40.2)$ & $2214(35.9)$ & $2642(35.5)$ & $2584(38.4)$ & $2723(37.0)$ \\
\hline Obese & $16,293(33.0)$ & $2033(29.0)$ & $2260(31.0)$ & $2405(32.8)$ & $2125(34.5)$ & $2625(35.3)$ & $2280(33.9)$ & $2565(34.8)$ \\
\hline Overweight & $13,191(26.7)$ & $1948(27.8)$ & $1928(26.4)$ & $1866(25.4)$ & $1721(27.9)$ & $2042(27.5)$ & $1741(25.9)$ & $1945(26.4)$ \\
\hline Underweight & $842(1.71)$ & $126(1.80)$ & $113(1.55)$ & $123(1.68)$ & $100(1.62)$ & $125(1.68)$ & $121(1.80)$ & $134(1.82)$ \\
\hline PIR (median (IQR)) & $1.89(2.74)$ & $2.12(2.89)$ & $1.84(2.64)$ & $2.09(2.73)$ & $1.92(2.68)$ & $1.78(2.58)$ & $1.70(2.79)$ & $1.79(2.81)$ \\
\hline $\begin{array}{l}\text { Serum cotinine detection } \\
\text { rate }(n \%)^{b}\end{array}$ & $38,236(77.5)$ & $5425(77.3)$ & $6056(83.1)$ & $6063(82.6)$ & $5125(83.2)$ & $5708(76.8)$ & $4873(72.5)$ & $4986(67.7)$ \\
\hline $\begin{array}{l}\text { Serum cotinine }(\mathrm{ng} / \mathrm{mL} \text {, } \\
\text { median }(\mathrm{IQR}))\end{array}$ & $0.06(1.13)$ & $0.08(1.31)$ & $0.10(1.44)$ & $0.07(1.10)$ & $0.07(1.51)$ & $0.04(1.00)$ & $0.04(0.60)$ & $0.04(0.90)$ \\
\hline \multicolumn{9}{|c|}{ Cotinine exposure category $(n, \%)$} \\
\hline Active smokers (>10 ng/mL) & $9102(18.45)$ & $1286(18.33)$ & $1355(18.58)$ & $1326(18.06)$ & $1206(19.58)$ & $1428(19.21)$ & $1154(17.16)$ & $1347(18.28)$ \\
\hline $\begin{array}{l}\text { Passive smokers (1-10 ng/ } \\
\text { mL) }\end{array}$ & $3631(7.36)$ & $598(8.52)$ & $678(9.30)$ & $566(7.71)$ & $485(7.87)$ & $442(5.95)$ & $389(5.78)$ & $473(6.42)$ \\
\hline Nonsmokers $(<1$ ng/mL) & $36,605(74.19)$ & $5133(73.15)$ & $5258(72.12)$ & $5451(74.23)$ & $4469(72.55)$ & $5564(74.84)$ & $5183(77.06)$ & $5547(75.30)$ \\
\hline \multicolumn{9}{|l|}{ Tobacco/nicotine use $(n, \%)^{\mathrm{c}}$} \\
\hline Yes & $8441(20.6)$ & $1259(20.7)$ & $1247(20.5)$ & $1251(20.5)$ & $1150(22.8)$ & $1300(21.0)$ & $1070(19.6)$ & $1164(19.4)$ \\
\hline No & $29,696(72.5)$ & 4505 (73.9) & $4415(72.6)$ & $4463(73.2)$ & $3619(71.7)$ & $4331(70.0)$ & 3914 (71.6) & $4449(74.0)$ \\
\hline Missing & $2846(6.94)$ & $328(5.38)$ & $416(6.84)$ & $384(6.30)$ & $280(5.55)$ & $558(9.02)$ & $479(8.77)$ & $401(6.67)$ \\
\hline \multicolumn{9}{|l|}{ Alcohol consumption $(n, \%)^{\mathrm{d}}$} \\
\hline Yes & $20,805(65.8)$ & $2682(65.5)$ & $2674(64.5)$ & $2721(64.5)$ & $2797(66.8)$ & $3415(66.6)$ & $3131(66.5)$ & $3385(65.7)$ \\
\hline No & $8502(26.9)$ & $1204(29.4)$ & $1181(28.5)$ & $1232(29.2)$ & $1161(27.7)$ & $1213(23.7)$ & $1121(23.8)$ & $1390(27.0)$ \\
\hline Missing & $2321(7.34)$ & $211(5.15)$ & $289(6.97)$ & $265(6.28)$ & $228(5.45)$ & $496(9.68)$ & $456(9.69)$ & $376(7.30)$ \\
\hline $\begin{array}{l}\text { Serum } 25(\mathrm{OH}) \mathrm{D}(\mathrm{nmol} / \mathrm{L} \text {, } \\
\quad \text { median }(\mathrm{IQR}))\end{array}$ & $59.2(30.4)$ & $56.3(26.2)$ & $58.1(29.5)$ & $56.8(26.7)$ & $61.8(31.3)$ & $62.1(32.0)$ & $60.7(32.8)$ & $61.7(30.7)$ \\
\hline \multicolumn{9}{|l|}{ VD status category $(n, \%)$} \\
\hline $\begin{array}{l}\text { Deficiency } \\
\qquad(<30 \mathrm{nmol} / \mathrm{L} ;<12 \mathrm{ng} / \mathrm{mL})\end{array}$ & $3764(7.63)$ & $490(6.98)$ & $709(9.72)$ & $522(7.11)$ & $494(8.02)$ & $544(7.32)$ & $488(7.26)$ & $517(7.02)$ \\
\hline $\begin{array}{l}\text { Inadequacy }(30-50 \mathrm{nmol} / \mathrm{L} \text {; } \\
\quad 12-20 \mathrm{ng} / \mathrm{mL})\end{array}$ & $12,718(25.8)$ & $2105(30.0)$ & $1860(25.5)$ & $2362(32.2)$ & $1425(23.1)$ & $1661(22.3)$ & $1682(25.0)$ & $1623(22.0)$ \\
\hline $\begin{array}{l}\text { Adequacy } \\
\qquad(\geq 50 \mathrm{nmol} / \mathrm{L} ; \geq 20 \mathrm{ng} / \mathrm{mL})\end{array}$ & $32,176(65.2)$ & $4388(62.5)$ & $4662(63.9)$ & $4421(60.2)$ & $4164(67.6)$ & $5096(68.5)$ & $4397(65.4)$ & $5048(68.5)$ \\
\hline $\begin{array}{l}\text { Intoxication } \\
\qquad(>125 \mathrm{nmol} / \mathrm{L} ;>50 \mathrm{ng} / \mathrm{mL})\end{array}$ & $680(1.38)$ & $34(0.48)$ & $60(0.82)$ & $38(0.52)$ & $77(1.25)$ & $133(1.79)$ & $159(2.36)$ & $179(2.43)$ \\
\hline \multicolumn{9}{|l|}{ Oral contraceptives use $(n, \%)^{\mathrm{e}}$} \\
\hline Yes & $10,590(50.7)$ & $1445(45.7)$ & $1393(45.4)$ & $1545(49.3)$ & $1402(55.3)$ & $1668(53.3)$ & $1455(53.0)$ & $1682(53.9)$ \\
\hline No & $8361(40.0)$ & $1441(45.6)$ & $1410(46.0)$ & $1334(42.5)$ & $946(37.3)$ & $1092(34.9)$ & $982(35.8)$ & $1156(37.1)$ \\
\hline Missing & $1937(9.27)$ & $273(8.64)$ & $262(8.55)$ & $257(8.20)$ & $185(7.30)$ & $372(11.90)$ & $308(11.20)$ & $280(8.98)$ \\
\hline \multicolumn{9}{|c|}{ Self-reported kidney health $(n, \%)^{\mathrm{f}}$} \\
\hline Healthy & $841(2.70)$ & $97(2.37)$ & $106(2.56)$ & $108(2.56)$ & $120(2.87)$ & $112(2.19)$ & $145(3.24)$ & $153(3.13)$ \\
\hline Weak/fail & $30,233(97.1)$ & $3988(97.3)$ & $4033(97.3)$ & $4098(97.2)$ & $4059(97.0)$ & $5005(97.7)$ & $4326(96.7)$ & $4724(96.7)$ \\
\hline Missing & $52(0.17)$ & $12(0.29)$ & $5(0.12)$ & $12(0.28)$ & $7(0.17)$ & $7(0.14)$ & $3(0.07)$ & $6(0.12)$ \\
\hline \multicolumn{9}{|l|}{ Vigorous activity $(n, \%)^{\mathrm{d}}$} \\
\hline Yes & $16,496(40.3)$ & $2660(43.7)$ & $2342(38.5)$ & $2663(43.7)$ & 1978 (39.2) & $2338(37.8)$ & 2123 (38.9) & $2392(39.8)$ \\
\hline
\end{tabular}


Table 1 (continued)

\begin{tabular}{|c|c|c|c|c|c|c|c|c|}
\hline & $\begin{array}{l}\text { Overall } \\
(N=49,338)\end{array}$ & $\begin{array}{l}\text { 2001-2002 } \\
(N=7017)\end{array}$ & $\begin{array}{l}\text { 2003-2004 } \\
(N=7291)\end{array}$ & $\begin{array}{l}\text { 2005-2006 } \\
(N=7343)\end{array}$ & $\begin{array}{l}\mathbf{2 0 0 7 - 2 0 0 8} \\
(N=6160)\end{array}$ & $\begin{array}{l}\mathbf{2 0 0 9 - 2 0 1 0} \\
(N=7434)\end{array}$ & $\begin{array}{l}\text { 2011-2012 } \\
(N=6726)\end{array}$ & $\begin{array}{l}\text { 2013-2014 } \\
(N=7367)\end{array}$ \\
\hline No & $24,258(59.2)$ & $3386(55.6)$ & $3684(60.6)$ & $3386(55.5)$ & $3044(60.3)$ & $3830(61.9)$ & $3325(60.9)$ & $3603(59.9)$ \\
\hline Missing & $229(0.56)$ & $46(0.76)$ & $52(0.86)$ & $49(0.80)$ & $27(0.53)$ & $21(0.34)$ & $15(0.27)$ & $19(0.32)$ \\
\hline \multicolumn{9}{|c|}{ Moderate activity $(n, \%)^{\mathrm{d}}$} \\
\hline Yes & $23,604(57.6)$ & 3091 (50.7) & $3429(56.4)$ & 3532 (57.9) & 2999 (59.4) & $3646(58.9)$ & $3272(59.9)$ & $3635(60.4)$ \\
\hline No & $17,141(41.8)$ & $2952(48.5)$ & $2594(42.7)$ & 2517 (41.3) & $2022(40.0)$ & $2521(40.7)$ & $2177(39.8)$ & $2358(39.2)$ \\
\hline Missing & $238(0.58)$ & $49(0.80)$ & $55(0.90)$ & $49(0.80)$ & $28(0.55)$ & $22(0.36)$ & $14(0.26)$ & $21(0.35)$ \\
\hline \multicolumn{9}{|c|}{ VD consumption during past $24 \mathrm{~h}(n, \%)^{\mathrm{g}}$} \\
\hline Yes & $25,565(92.3)$ & - & - & - & $5845(94.9)$ & 7077 (95.2) & $6150(91.4)$ & $6493(88.1)$ \\
\hline No & $454(1.64)$ & - & - & - & $75(1.22)$ & $102(1.37)$ & $97(1.44)$ & $180(2.44)$ \\
\hline Missing & $1668(6.02)$ & - & - & - & $240(3.90)$ & $255(3.43)$ & 479 (7.12) & 694 (9.42) \\
\hline
\end{tabular}

$I Q R$ inter quartile range, $B M I$ body mass index, $P I R$ ratio of family income to poverty

${ }^{a}$ The number of included participants was 49,338, with complete data on age, ethnicity/race, BMI, PIR, serum cotinine, and 25 (OH) D levels within each cycle in NHANES 2001-2014

${ }^{b}$ Detection rate: at or above detection limit

${ }^{\mathrm{c}}$ Only participants aged $\geq 12$ years have data on the variable

${ }^{\mathrm{d}}$ Only participants aged $\geq 20$ years in NHANES 2001-2010, and participants aged $\geq 18$ years in NHANES 2011-2014 have data on the variable

${ }^{e}$ Only female participants aged $\geq 12$ years have data on the variable

${ }^{\mathrm{f}}$ Only participants aged $\geq 20$ years have data on the variable

${ }^{\mathrm{g}}$ Only those participated in NHANES 2007 and later have data on vitamin D consumption during past $24 \mathrm{~h}$

NHANES 2011-2014). The physical activity questionnaires were established on the basis of the Global Physical Activity Questionnaires (GPAQ) and included activity at different intensity (moderate, vigorous) cross multiple domains (recreational and at work). We have merged the activity across different domains (at work and recreational) into total physical activity category, that is, moderate activity and vigorous activity for participants aged 12 years and older when available. For participants aged 20 and over, self-reported kidney health condition was also collected from the question "Ever told you had weak/failing kidneys?" The variables adjusted in the final analyses included gender (female, male), age (continuous), ethnicity/race (Mexican American, other Hispanic, non-Hispanic white, non-Hispanic black, other race), PIR (continuous), BMI (categorical), alcohol use (dichotomous), vigorous activity (dichotomous), moderate activity (dichotomous), kidney health condition (weak, healthy), and NHANES cycle (categorical). Oral use of contraceptives (dichotomous) was additionally adjusted for females aged 12 and over. List of detailed variable characteristics is presented in Table 1.

\section{Statistical analysis}

The serum cotinine and $25(\mathrm{OH}) \mathrm{D}$ were natural-log transformed (In-transformed) to improve the normality in the analyses. Cotinine and 25(OH)D were modeled as both continuous (In-transformed) and categorical variables. In the base model, we fitted multiple linear regression models to evaluate the linear association between serum cotinine and $25(\mathrm{OH}) \mathrm{D}$ concentrations. We first applied the models by combining all seven cycles together without considering change in risk over time. The temporal variation of the association was then evaluated by a stratification model, which estimated and compared separate associations for each cycle to examine whether the associations were consistent across all cycles. Then logistic regression models were fitted to further investigate relationships between tobacco smoke exposure categories with different VD status. Meanwhile, all the analyses were performed for pooled cycles (2001-2014), and for each cycle separately to examine whether the associations are consistent over time.

Furthermore, we performed the stratified analyses by age, gender, ethnicity/race, and BMI categories to examine potential modifying effects of demographic factors as well as to verify the robustness of our findings. Because cotinine levels can vary greatly by gender and age, the analyses were further stratified by age group $(3-11,12-19,20-59, \geq 60$ years) in both females and males, generally consistent with the age groupings defined in the NHANES Sample Design reports (CDC 2021). In addition, the dietary vitamin D intake variable has been added to NHANES survey using a 24-h dietary recall interview for participants of all age since 2007. Thus, we included the adjustment for self-reported VD intakes in the sensitivity analysis for NHANES 2007-2014. Results of all analyses were presented as $\beta$ coefficients (continuous) and odds ratios (ORs; categorical), with corresponding 95\% confidence intervals (CIs). All the statistical analyses were 
conducted using $\mathrm{R}$ (version 3.4). $P$ value $<0.05$ was deemed as statistically significant (two-tailed).

\section{Results}

Table 1 summarizes the demographic characteristics, variables related to tobacco smoke exposure, and VD status of all participants across the seven survey cycles. A total of 49,338 participants were included in these study, with 7017 from 2001 to 2002, 7291 from 2003 to 2004, 7343 from 2005 to 2006,6160 from 2007 to 2008,7434 from 2009 to 2010, 6726 from 2011 to 2012, and 7367 from 2013 to 2014. The distributions of the general characteristics for overall sample by gender-age status are shown in Supplementary Table 1. Among 49,338 participants, there were 24,987 (50.6\%) females and 24,351 (49.4\%) males. The mean age of all participants was 35.2 years $( \pm 23.1$ years), and the distribution of age subgroups was 8355 (16.9\%) for 3-11, 9857 (20.0\%) for $12-19,21,012(42.6 \%)$ for $20-59$, and 10,114 $(20.5 \%)$ for $\geq 60$ years.

\section{Tobacco smoke exposure prevalence}

Figure 1 illustrates the trends of serum cotinine levels through the NHANES 2001-2014 period. Comparing the overall median concentrations of serum cotinine in NHANES 2001-2002 (0.08 $\mathrm{ng} / \mathrm{mL})$ and NHANES 2013-2014 (0.04 ng/mL), a decrease of 50\% was observed (Table 1). The percentage of NHANES participants with active smoking exposure (serum cotinine level $>10 \mathrm{ng}$ / $\mathrm{mL}$ ) stabilized between 17.2 and $19.6 \%$ over the 14-year period. Meanwhile, the proportion of participants with passive smoking exposure (1-10 ng/mL) showed the comparatively downward trends over time, with the prevalence in NHANES 2013-2014 decreased to 6.4\% (compared to $8.5 \%$ in NHANES 2001-2002).

For the overall sample covering all the cycles, the percentage of active smokers across different age groups were $0.4 \%$ for children aged $3-11$ years, $13.0 \%$ for adolescents aged $12-19$ years, $68.5 \%$ for adults aged $20-59$ years, and $18.1 \%$ for adults aged $\geq 60$ years (Supplementary Table 1 ). In addition, compared with other age groups, children aged

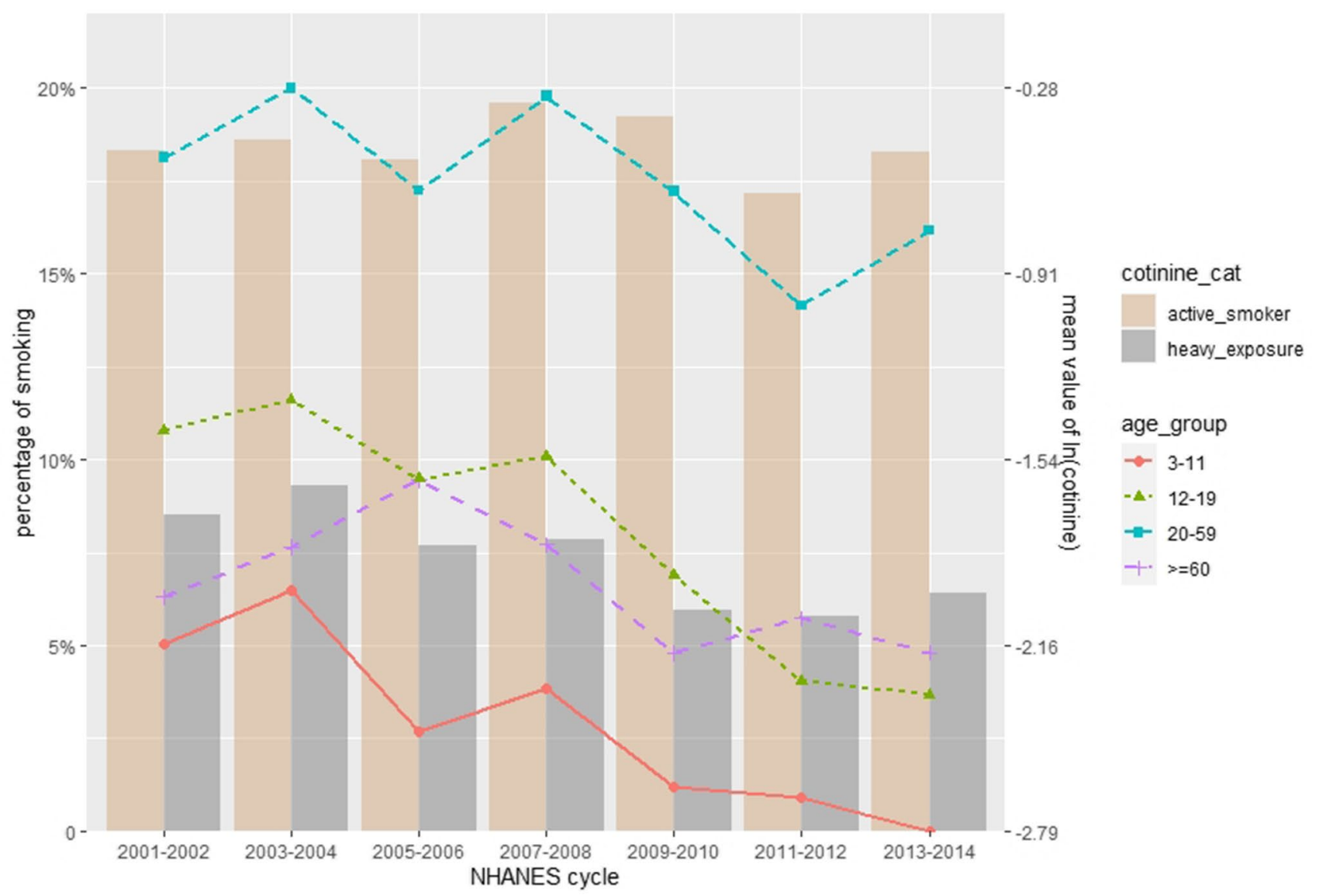

Fig. 1 Estimated prevalence (\%) of active smoking (brown bars) and passive smoking (gray bars) exposure among US population aged $\geq 3$ years. Notes: Geometric mean serum cotinine levels (ng/ $\mathrm{mL}$ ) plotted on the ln scale for children aged 3-11 years (orange cir- cles, solid line) and adolescents aged 12-19 years (green triangles, dashed line), adults aged 20-59 years (blue squares, dashed line), and aged $\geq 60$ years (purple crosses, dashed line) in the NHANES 20012014 by survey cycles; data shown in Supplementary Table 1 
3-11 have a higher percentage of passive smoking exposure $(32.1 \%)$.

\section{Suboptimal VD status occurrence}

Table 2 describes the population characteristics by vitamin $\mathrm{D}$ status. During the entire study period (2001-2014), the overall prevalence of VD deficiency, inadequacy and intoxication is 7.6, 25.8 and $1.4 \%$, respectively. The median concentration was reported to be $24.4,41.3,68.5$, and $138 \mathrm{nmol} / \mathrm{L}$ for VD deficiency, inadequacy, sufficiency, and intoxication, respectively. VD deficiency prevalence was relatively stable among different cycles. While the prevalence of VD inadequacy in the 1st cycle decreased from $30.0 \%$ to the end of the study (20.0\%), with the prevalence of VD adequacy increased from 62.5 to $68.5 \%$ (Table 1). Obvious increasing trends for VD intoxication were also illustrated. Compared to VD intoxication in NHANES 2001-2002, the prevalence increased from 0.43 to $2.43 \%$ in 2013-2014. In particular, participants who were female, non-Hispanic Black, obese, and having higher levels of serum cotinine had higher percentage of VD deficiency or inadequacy. And the prevalence of VD intoxication was observed higher for female, nonHispanic White, oral contraceptive users, and participants doing moderate activities.

\section{Association between tobacco smoke exposure and VD levels}

In the base model, we first calculated the associations between tobacco smoke exposure and VD levels for the entire study period without considering the temporal variation. The overall coefficient for the linear association between continuous serum cotinine and $25(\mathrm{OH}) \mathrm{D}$ was estimated to be -0.011 (95\% CI: - 0.012-- 0.01), which indicated that cotinine concentration was negatively associated with VD level (Table 3). Next we evaluated whether the risks varied over time using stratification models for different cycles. The coefficients were all negative for all datasets with slight increase in associations over time: for NHANES 2001-2002, 2003-2004, 2005-2006, 2007-2008, 2009-2010, 2011-2012, and 2013-2014, the adjusted coefficients were -0.007 (95\% CI: -0.009 to -0.004$),-0.008$ (95\% CI: -0.011 to -0.005 ), -0.006 (95\% CI: -0.008 to -0.004$),-0.008$ (95\% CI: -0.011 to -0.005$),-0.014$ (95\% CI: -0.017 to -0.012$),-0.015$ (95\% CI: -0.018 to -0.012$),-0.013$ (95\% CI: -0.016 to -0.011 ), respectively.

More specifically, pooled analysis of associations between tobacco smoke categories and VD status showed adverse effects of active smoking on VD inadequacy $(\mathrm{OR}=1.51$, 95\% CI: $1.43-1.61)$ and VD deficiency (OR $=2.24,95 \%$ CI: 2.05-2.45). A positive association between passive smoking and VD deficiency was also observed $(\mathrm{OR}=1.30$, 95\% CI: 1.14-1.48) for the entire study period (Table 4). Results for the stratified analysis indicated that the associations between tobacco smoke exposure and VD status within different cycles were mostly consistent with the pooled samples. We observed a similar temporal trend to the base model, namely, that the overall risk of VD deficiency and inadequacy related to active smoking exposure increased over time, whereas estimations for passive smoking exposure showed less pronounced and less consistent impacts on VD deficiency and inadequacy among different cycles. For NHANES 2001-2002, and 2010-2011, the associations were additionally positive for passive smoke exposure and VD deficiency; the odds ratios were evaluated to be 1.74 (95\% CI: $1.25-2.42)$ and 1.59 (95\% CI: 1.09-2.32), respectively. Moreover, the associations evidenced between tobacco smoke exposures and VD intoxication were not consistent for different NHANES datasets. For instance, in NHANES 2005-2006, both active and passive smoke exposures were positively associated with VD intoxication $\left(\mathrm{OR}_{\text {Active }}=2.17,95 \% \mathrm{CI}: 1.00-4.73 ; \mathrm{OR}_{\text {Passive }}=3.35 ; 95 \% \mathrm{CI}\right.$ : 1.20-9.31), and a positive relationship was also proved for active smoking in NHANES 2013-2014 (OR $=1.50,95 \%$ CI: 1.00-2.25). However, this positive relationship was weak since it was not supported by all sub-datasets.

\section{Modification effects by age, gender, ethnicity/race and BMI}

Since the associations between tobacco smoke exposure and VD levels were mostly consistent for the entire period and among cycles, the modification effects by demographic factors were examined combing all the cycles from 2001 to 2014. Figure 2 and Supplementary Table 2 present the linear associations between serum cotinine and VD concentrations by age-gender groups. Among children aged 3-11 years, serum cotinine was consistently positively associated with 25(OH)D concentrations, and showed a more pronounced estimate for females. Similarly, positive associations of serum cotinine with $25(\mathrm{OH}) \mathrm{D}$ were detected for all adolescents, and persisted only among male adolescents. For adults (20-59 and $\geq 60$ years), significant inverse associations for decreasing $25(\mathrm{OH}) \mathrm{D}$ concentrations with increasing levels of continuous cotinine were revealed, and the associations were more evident for females.

Figure 3 and Supplementary Table 3 show associations between tobacco smoke exposure categories and varied VD status within age-gender groups. For active smoking exposure, the estimates for children could not be derived due to small sizes $(34,0.4 \%)$. Active smoking was proved to be related with decreased risk of VD deficiency for adolescents aged $12-19$ years $(\mathrm{OR}=0.62,95 \%$ CI: $0.47-0.81)$. In genderstratified analyses, the protective effects remained consistent 
Table 2 Population characteristics by VD status in NHANES 2001-2014

\begin{tabular}{|c|c|c|c|c|}
\hline & $\begin{array}{l}\text { Deficiency } \\
N=3764\end{array}$ & $\begin{array}{l}\text { Inadequacy } \\
N=12,718\end{array}$ & $\begin{array}{l}\text { Adequacy } \\
N=32,176\end{array}$ & $\begin{array}{l}\text { Intoxication } \\
N=680\end{array}$ \\
\hline Age (year, mean (SD)) & $36.8(20.1)$ & $34.9(21.6)$ & $34.9(23.9)$ & $48.6(23.5)$ \\
\hline \multicolumn{5}{|l|}{$\operatorname{Sex}(n, \%)$} \\
\hline Female & $2268(60.3)$ & $6653(52.3)$ & $15,568(48.4)$ & $498(73.2)$ \\
\hline Male & $1496(39.7)$ & $6065(47.7)$ & $16,608(51.6)$ & $182(26.8)$ \\
\hline \multicolumn{5}{|l|}{ Race $(n, \%)$} \\
\hline Hispanic & $795(21.1)$ & $4208(33.1)$ & $8833(27.5)$ & $44(6.5)$ \\
\hline Non-Hispanic Black & $2220(59.0)$ & $4690(36.9)$ & 4465 (13.9) & $59(8.7)$ \\
\hline Non-Hispanic White & $466(12.4)$ & 2749 (21.6) & $16,511(51.3)$ & $531(78.1)$ \\
\hline Other race & $283(7.5)$ & $1071(8.4)$ & $2367(7.4)$ & $46(6.8)$ \\
\hline BMI $\left(\mathrm{kg} / \mathrm{m}^{2}\right.$, mean $\left.(\mathrm{SD})\right)$ & $29.9(9.2)$ & $27.5(7.5)$ & $25.1(6.9)$ & $25.2(5.8)$ \\
\hline \multicolumn{5}{|l|}{ BMI category $(n, \%)$} \\
\hline Normal/underweight & $1177(31.3)$ & $4298(33.8)$ & $14,013(43.6)$ & $366(53.8)$ \\
\hline Obese & $1771(47.1)$ & $5116(40.2)$ & $9282(28.8)$ & $124(18.2)$ \\
\hline Overweight & $816(21.7)$ & $3304(26.0)$ & $8881(27.6)$ & $190(27.9)$ \\
\hline \multicolumn{5}{|l|}{ NHANES cycle $(n, \%)$} \\
\hline 2001-2002 & $490(13.0)$ & 2105 (16.6) & $4388(13.6)$ & $34(5.0)$ \\
\hline 2003-2004 & $709(18.8)$ & $1860(14.6)$ & $4662(14.5)$ & $60(8.8)$ \\
\hline 2005-2006 & $522(13.9)$ & $2362(18.6)$ & $4421(13.7)$ & $38(5.6)$ \\
\hline 2007-2008 & $494(13.1)$ & $1425(11.2)$ & 4164 (12.9) & $77(11.3)$ \\
\hline 2009-2010 & $544(14.5)$ & $1661(13.1)$ & $5096(15.8)$ & $133(19.6)$ \\
\hline 2011-2012 & $488(13.0)$ & $1682(13.2)$ & $4397(13.7)$ & $159(23.4)$ \\
\hline 2013-2014 & $517(13.7)$ & $1623(12.8)$ & $5048(15.7)$ & $179(26.3)$ \\
\hline PIR (median (IQR)) & $1.6(2.1)$ & $1.6(2.3)$ & $2.1(3.0)$ & $3.2(3.6)$ \\
\hline Serum cotinine (ng/mL, median (IQR)) & $0.18(25.67)$ & $0.08(1.82)$ & $0.05(0.76)$ & $0.03(0.43)$ \\
\hline \multicolumn{5}{|l|}{ Cotinine exposure category $(n, \%)$} \\
\hline Active smokers (> $10 \mathrm{ng} / \mathrm{mL})$ & $1016(27.0)$ & $2609(20.5)$ & $5354(16.6)$ & $123(18.1)$ \\
\hline Passive smokers (1-10 ng/mL) & $368(9.8)$ & $960(7.6)$ & $2277(7.1)$ & $26(3.8)$ \\
\hline Nonsmokers $(<1 \mathrm{ng} / \mathrm{mL})$ & $2380(63.2)$ & 9149 (71.9) & $24,545(76.3)$ & $531(78.1)$ \\
\hline Serum 25(OH)D (nmol/L, median (IQR)) & $24.4(6.9)$ & $41.3(9.9)$ & $68.5(21.8)$ & $138(19.0)$ \\
\hline \multicolumn{5}{|l|}{ VD consumption during past $24 \mathrm{~h}(n, \%)$} \\
\hline Yes & $1851(96.8)$ & $5868(97.8)$ & $17,339(98.6)$ & $507(98.3)$ \\
\hline No & $61(3.2)$ & $135(2.25)$ & $249(1.42)$ & $9(1.74)$ \\
\hline \multicolumn{5}{|l|}{ Tobacco/nicotine use $(n, \%)$} \\
\hline Yes & $904(27.2)$ & $2361(22.6)$ & $5069(21.3)$ & $107(18.1)$ \\
\hline No & $2417(72.8)$ & $8090(77.4)$ & $18,704(78.7)$ & 485 (81.9) \\
\hline \multicolumn{5}{|l|}{ Alcohol consumption $(n, \%)$} \\
\hline Yes & $1603(64.5)$ & $5014(66.3)$ & $13,800(73.7)$ & $388(72.7)$ \\
\hline No & $884(35.5)$ & $2546(33.7)$ & $4926(26.3)$ & $146(27.3)$ \\
\hline \multicolumn{5}{|l|}{ Oral contraceptives use $(n, \%)$} \\
\hline Yes & $1006(51.5)$ & $2591(49.0)$ & $6668(59.2)$ & $325(73.0)$ \\
\hline No & $946(48.5)$ & $2700(51.0)$ & $4595(40.8)$ & $120(27.0)$ \\
\hline \multicolumn{5}{|l|}{ Self-reported kidney health $(n, \%)$} \\
\hline Healthy & $2603(97.0)$ & $7850(97.0)$ & $19,232(97.5)$ & $548(95.3)$ \\
\hline Weak/fail & $81(3.0)$ & $239(3.0)$ & $494(2.5)$ & $27(4.7)$ \\
\hline \multicolumn{5}{|l|}{ Vigorous activity $(n, \%)$} \\
\hline Yes & $1181(32.7)$ & $4367(38.7)$ & $10,702(42.4)$ & $246(38.5)$ \\
\hline No & $2431(67.3)$ & $6906(61.3)$ & $14,528(57.6)$ & $393(61.5)$ \\
\hline \multicolumn{5}{|l|}{ Moderate activity $(n, \%)$} \\
\hline Yes & $1711(47.4)$ & $5930(52.6)$ & 15,555 (61.7) & $408(63.8)$ \\
\hline No & 1901 (52.6) & $5341(47.4)$ & $9668(38.3)$ & $231(36.2)$ \\
\hline
\end{tabular}


for VD deficiency in both females and males. But some differences were displayed. Specifically, among female active smokers, an inverse association was also shown for VD inadequacy (OR $=0.70,95 \% \mathrm{CI}: 0.52-0.94)$. Moreover, we observed a strongly positive relationship of active smoking with VD intoxication in male adolescents $(\mathrm{OR}=4.02,95 \% \mathrm{CI}$ : $1.36-11.90)$. Among adults aged between 20 and 59 years, active smoking was associated with increased risk of VD deficiency $(\mathrm{OR}=1.67,95 \% \mathrm{CI}: 1.47-1.90)$ and inadequacy $(\mathrm{OR}=1.21$, 95\% CI: 1.11-1.32). Among female adults, the positive associations and patterns across smoke exposure and VD categories were similar to those in all participants. In male adults, only positive effect on VD deficiency risk remained $(\mathrm{OR}=1.41$, 95\% CI: 1.17-1.70). Besides, active smoking in participants aged $\geq 60$ years was related with VD deficiency $(\mathrm{OR}=2.30$, 95\% CI: $1.85-2.86)$ as well as inadequacy (OR $=1.75,95 \%$ CI: 1.52-2.01). Consistent relations were shown after stratifying by gender.

For passive smoking exposures, there was no evidence of significant associations of passive smoking exposure with VD status among children and adolescents. For adults aged between 20 and 59 years, passive smoking exposure was positively associated with VD deficiency (OR $=1.60,95 \% \mathrm{CI}: 1.28-2.00)$. Furthermore, female adults exposed to higher levels of passive smoking were associated with a higher risk of VD intoxication $(\mathrm{OR}=1.97$, 95\% CI: 1.02-3.80). Among participants aged $\geq 60$ years, passive smoking exposure was positively associated with increased risk of VD deficiency (OR=2.04, 95\% CI: 1.37-3.03).

When stratified by ethnicity/race, the associations between active smoking and VD deficiency were significant in all race groups in Table 5. Specifically, the association was relatively stronger in non-Hispanic participants when compared with Hispanic and other races. Across ethnicity/race groups, the associations and patterns of active smoking and VD inadequacy were similar to those of VD deficiency. In addition, for Hispanic participants, a strongly positive association was shown between active smoking exposure and VD intoxication (OR $=3.41,95 \%$ CI: 1.72-6.77). Passive smoking exposure was positively associated with VD deficiency among participants whose races are Hispanic (OR = 1.70, 95\% CI: 1.25-2.31) and non-Hispanic black (OR $=1.22,95 \% \mathrm{CI}: 1.04-1.44)$.

The associations of the active smoking exposure and VD deficiency as well inadequacy were consistently positive for participants across all BMI categories (Table 5). Meanwhile, passive smoking exposure of obese participants was also positively associated with VD deficiency $(\mathrm{OR}=1.31,95 \% \mathrm{CI}: 1.07-1.59)$.

\section{Results of sensitivity analysis}

To exclude the possible influence of VD intake, we further evaluated the effects of tobacco use exposure on VD status among participants aged 20-59 years with adjustment for 
Table 4 Associations between tobacco use exposure and suboptimal VD status by survey cycle in NHANES 2001-2014

\begin{tabular}{|c|c|c|c|c|c|c|c|c|c|}
\hline Exposure & $\begin{array}{l}\text { Suboptimal } \\
\text { VD status }\end{array}$ & $\begin{array}{l}\text { Entire } \\
\text { period } \\
(2001-2014)\end{array}$ & $\begin{array}{l}\text { Cycle } 1 \\
(2001- \\
2002)\end{array}$ & $\begin{array}{l}\text { Cycle } 2 \\
(2003- \\
2004)\end{array}$ & $\begin{array}{l}\text { Cycle } 3 \\
(2005- \\
2006)\end{array}$ & $\begin{array}{l}\text { Cycle } 4 \\
\text { (2007-2008) }\end{array}$ & $\begin{array}{l}\text { Cycle } 5 \\
(2009- \\
2010)\end{array}$ & $\begin{array}{l}\text { Cycle } 6 \\
(2011- \\
2012)\end{array}$ & $\begin{array}{l}\text { Cycle } 7 \\
(2013-2014)\end{array}$ \\
\hline \multirow[t]{3}{*}{$\begin{array}{l}\text { Active } \\
\text { smokers }\end{array}$} & Deficiency & $\begin{array}{l}2.24(2.05 \\
2.45)\end{array}$ & $\begin{array}{l}2.20(1.69, \\
2.86)\end{array}$ & $\begin{array}{l}2.12(1.71, \\
2.64)\end{array}$ & $\begin{array}{c}1.84(1.43, \\
2.38)\end{array}$ & $\begin{array}{l}1.69 \\
(1.32,2.17)\end{array}$ & $\begin{array}{l}2.58(2.05 \\
3.23)\end{array}$ & $\begin{array}{l}2.89(2.28, \\
3.68)\end{array}$ & $\begin{array}{l}2.78(2.20, \\
3.50)\end{array}$ \\
\hline & Inadequacy & $\begin{array}{l}1.51(1.43, \\
1.61)\end{array}$ & $\begin{array}{c}1.48(1.27, \\
1.72)\end{array}$ & $\begin{array}{l}1.45(1.25, \\
1.69)\end{array}$ & $\begin{array}{l}1.59(1.38, \\
1.85)\end{array}$ & $\begin{array}{l}1.42 \\
\quad(1.20,1.68)\end{array}$ & $\begin{array}{c}1.63(1.40, \\
1.90)\end{array}$ & $\begin{array}{l}1.55(1.32, \\
1.83)\end{array}$ & $\begin{array}{l}1.53(1.31, \\
1.79)\end{array}$ \\
\hline & Intoxication & $\begin{array}{c}1.11(0.90 \\
1.36)\end{array}$ & $\begin{array}{c}1.27(0.53, \\
3.05)\end{array}$ & $\begin{array}{l}1.48(0.77 \\
2.85)\end{array}$ & $\begin{array}{l}2.17(1.00, \\
4.73)\end{array}$ & $\begin{array}{l}1.26 \\
(0.70,2.24)\end{array}$ & $\begin{array}{c}0.71(0.42 \\
1.18)\end{array}$ & $\begin{array}{l}0.88(0.54 \\
1.44)\end{array}$ & $\begin{array}{l}1.50(1.00, \\
2.25)\end{array}$ \\
\hline \multirow[t]{3}{*}{$\begin{array}{l}\text { Passive } \\
\text { smokers }\end{array}$} & Deficiency & $\begin{array}{l}1.30(1.14, \\
1.48)\end{array}$ & $\begin{array}{c}1.74(1.25 \\
2.42)\end{array}$ & $\begin{array}{c}0.98(0.73, \\
1.32)\end{array}$ & $\begin{array}{c}1.34(0.97, \\
1.86)\end{array}$ & $\begin{array}{l}0.93 \\
\quad(0.62,1.39)\end{array}$ & $\begin{array}{c}1.30(0.88, \\
1.90)\end{array}$ & $\begin{array}{c}1.59(1.09 \\
2.32)\end{array}$ & $\begin{array}{l}1.25(0.88 \\
1.79)\end{array}$ \\
\hline & Inadequacy & $\begin{array}{l}0.99(0.91, \\
1.08)\end{array}$ & $\begin{array}{l}1.01(0.82, \\
1.25)\end{array}$ & $\begin{array}{l}0.94(0.77, \\
1.16)\end{array}$ & $\begin{array}{l}0.95(0.77, \\
1.18)\end{array}$ & $\begin{array}{l}1.13 \\
(0.88 .1 .45)\end{array}$ & $\begin{array}{l}0.91(0.70 \\
1.18)\end{array}$ & $\begin{array}{c}1.00(0.77, \\
1.29)\end{array}$ & $\begin{array}{c}0.88(0.69 \\
1.12)\end{array}$ \\
\hline & Intoxication & $\begin{array}{c}0.88(0.59, \\
1.32)\end{array}$ & NA & $\begin{array}{c}2.25(0.98, \\
5.13)\end{array}$ & $\begin{array}{l}3.35(1.20, \\
9.31)\end{array}$ & $\begin{array}{l}1.01 \\
(0.41,2.49)\end{array}$ & $\begin{array}{c}0.32(0.08, \\
1.30)\end{array}$ & $\begin{array}{l}0.22(0.03, \\
1.61)\end{array}$ & $\begin{array}{l}0.92(0.33, \\
2.59)\end{array}$ \\
\hline
\end{tabular}

Suboptimal VD levels were defined according to serum $25(\mathrm{OH}) \mathrm{D}$ concentration as deficiency $(<30 \mathrm{nmol} / \mathrm{L})$, inadequacy $(30-50 \mathrm{nmol} / \mathrm{L})$, and intoxication (>125 nmol/L). Data are odds ratios (95\% confidence intervals). "NA" indicates the estimates could not be derived in the group due to limited cases. Estimates were adjusted for age (continuous), gender (categorical)), ethnicity/race (categorical), PIR (continuous), and BMI (categorical)

dietary vitamin D intakes (Supplementary Table 4). Significant associations were shown for all types of tobacco smoke exposure and VD deficiency.

\section{Discussion}

Our research was based on a national long-term cross-sectional study including 49,338 participants aged $\geq 3$ years, revealing an increasing temporal trend in the association between tobacco smoke exposure and VD levels in the US general population during 2001 to 2014. The regression analyses for both pooled and separate cycles showed consistent effects of tobacco smoke exposure on suboptimal VD levels, with a slight increase in risk over time. Our overall results proved a negative association between serum cotinine and $25(\mathrm{OH}) \mathrm{D}$ concentrations, and that tobacco smoke exposure was related to suboptimal VD status, including VD inadequacy and deficiency.

Modification effects by several demographic characteristics on the associations further indicated that there was somewhat age- and gender- difference for the effects of
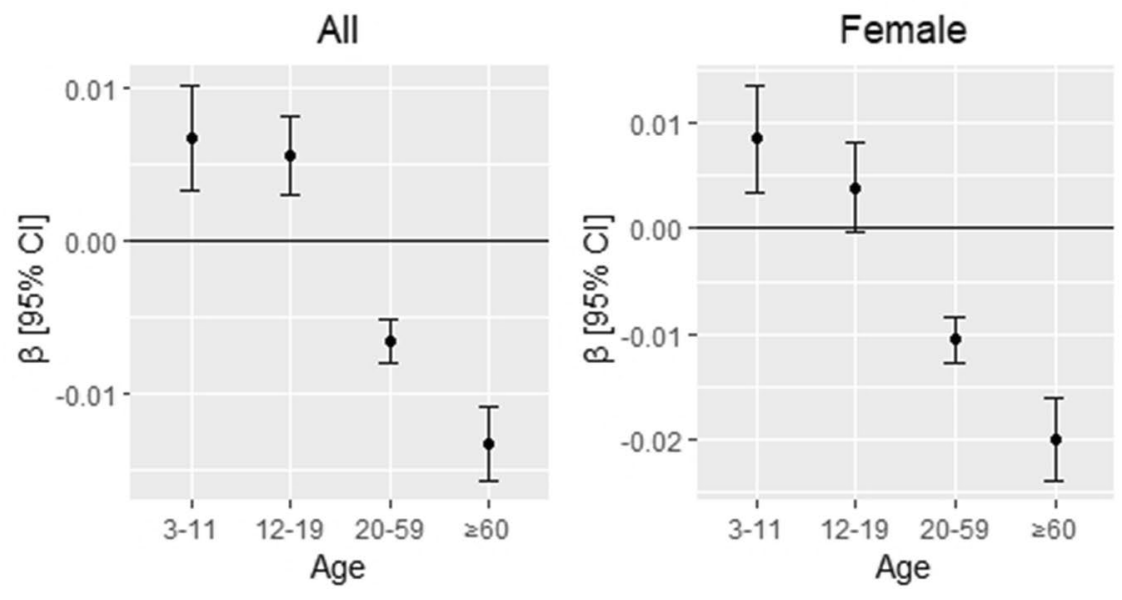

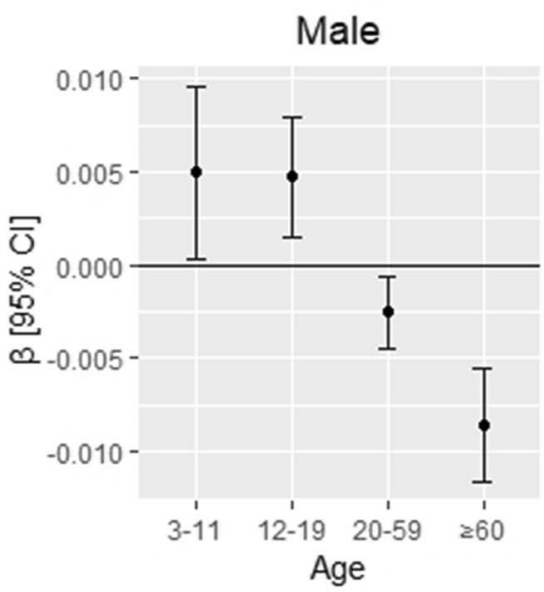

Fig. 2 Association between continuous serum cotinine and vitamin D by age-gender groups in NHANES 2001-2014. Notes: Both cotinine and vitamin D were ln-transformed. Estimates were presented as coefficients and $95 \%$ confidence intervals (CIs) and were adjusted for age (continuous), BMI (categorical), ethnicity/race (categorical),
PIR (continuous), and NHANES cycle (categorical). Gender was also adjusted in the total population, oral contraceptive use was adjusted for females aged $\geq 12$ years, and kidney health (categorical) was adjusted for participants aged $\geq 20$ years 

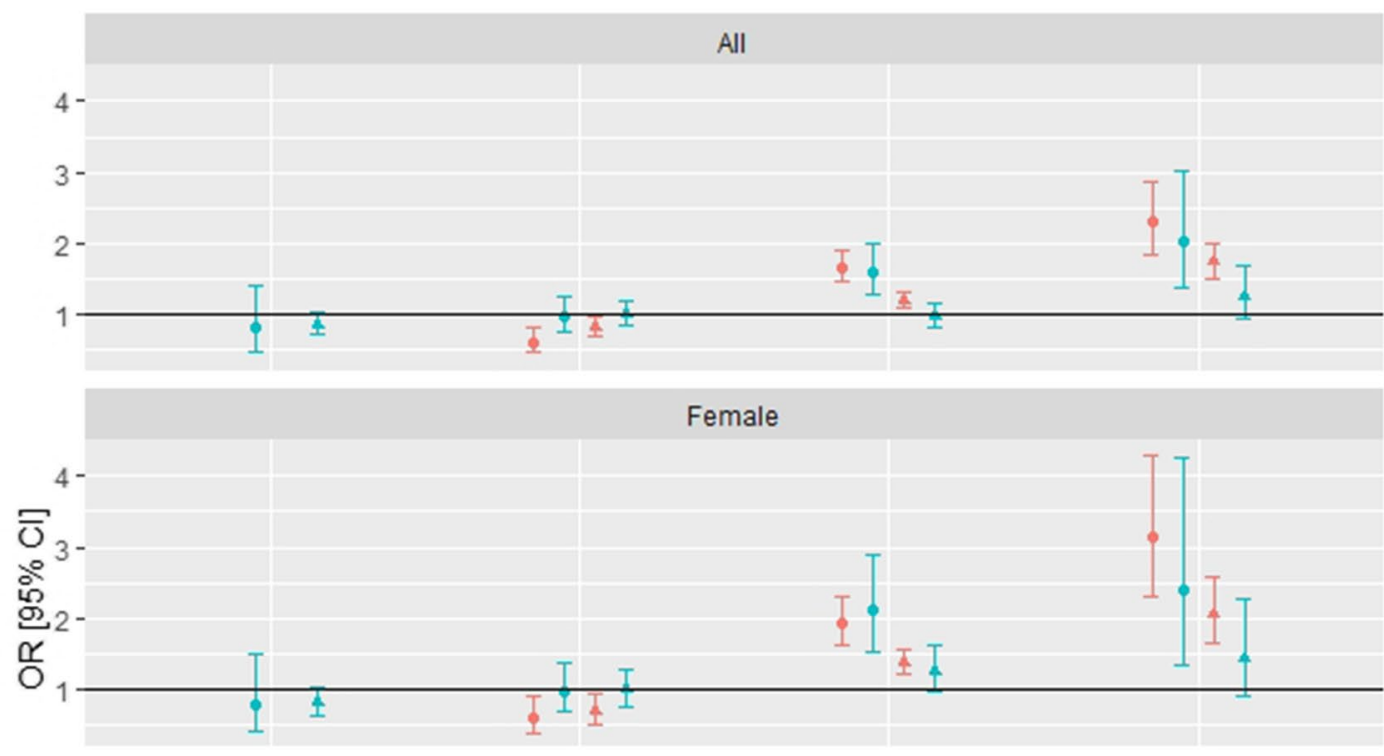

Cotinine_group

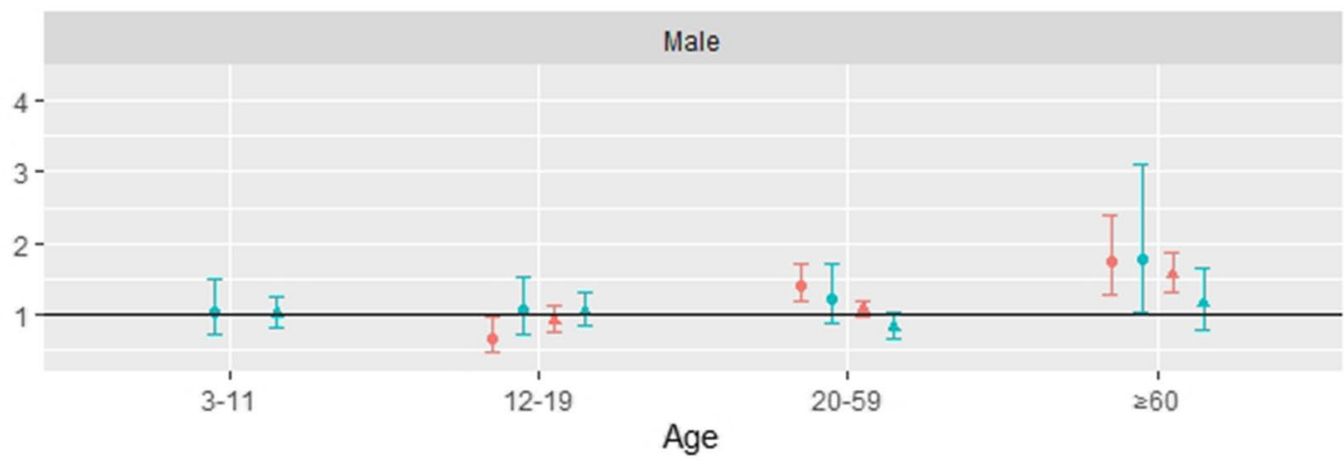

$\rightarrow$ Active smokers

$\rightarrow$ Heavy exposed

VitD_group

- Deficiency

- Inadequate

Fig. 3 Association between tobacco smoke exposure and VD status by age-gender groups in NHANES 2001-2014. Notes: Estimates were presented as odd ratios (ORs) and 95\% confidence intervals (CIs) and were adjusted for age (continuous), ethnicity/race (categorical), PIR (continuous), BMI (categorical), alcohol use (dichotomous; $\geq 12$ years), vigorous activity (dichotomous; $\geq 12$ years), moderate activity (dichotomous; $\geq 12$ years), kidney health condition

tobacco smoke exposure on VD levels. We found that serum cotinine presented a positive association with $25(\mathrm{OH}) \mathrm{D}$ concentrations in 3-11 years and 12-19 years old subgroups, whereas a negative relation was shown in 20-59 years and $\geq 60$ years old subgroups. No significant relationships were found between tobacco smoke exposure and VD status for children aged 3-11 years. Among active smokers aged 12-19 years, protective effects of tobacco smoke exposure were observed on VD deficiency as well as inadequacy. Both active and passive smoking were significantly associated with enhanced risk of VD deficiency in 20-59 years and $\geq 60$-year subgroups. Moreover, active smokers in 20-59-years and $\geq 60$-year old subgroups also had increased risk of VD inadequacy. After stratifying by gender, most of the above-mentioned effects persisted for both genders and (dichotomous; $\geq 20$ years), and NHANES cycle (categorical). Gender was also adjusted for total population, and oral use of contraceptives (dichotomous) was additionally adjusted for females aged $\geq 12$ years; the estimates could not be derived for active smoking exposure among children aged 3-11 years and passive smoking in adults aged $\geq 60$ years due to limited case sizes

were more pronounced in female participants. Our results also provided some evidence concerning impacts of tobacco smoke exposure on VD intoxication, which was rarely investigated in previous studies of the same content.

Our findings for linear relationship between tobacco smoke exposure and serum VD concentrations were partly supported by previous epidemiological studies. A Norwegian study on 205 participants aged $\geq 29$ years found that serum $25(\mathrm{OH}) \mathrm{D}$ levels were significantly lower in smokers than nonsmokers (Jorde et al. 2005). Results from 293 American females aged 18-45 years demonstrated significant decrease in serum 25-hydroxy-vitamin D3 (25$\mathrm{OHD}_{3}$ ) in both active and passive smokers (Soldin et al. 2011). A study of 181 Greece males aged 20-50 found that $25(\mathrm{OH}) \mathrm{D}$ was significantly lower in smokers compared to 
Table 5 Associations between tobacco use exposure and VD status by ethnicity/race groups in NHANES 2001-2014

\begin{tabular}{|c|c|c|c|c|}
\hline & Exposure & $\begin{array}{l}\text { Deficiency } \\
\text { OR }(95 \% \text { CI })\end{array}$ & $\begin{array}{l}\text { Inadequacy } \\
\text { OR }(95 \% \text { CI })\end{array}$ & $\begin{array}{l}\text { Intoxication } \\
\text { OR }(95 \% \mathrm{CI})\end{array}$ \\
\hline \multicolumn{5}{|l|}{ Ethnicity/race $^{\mathrm{a}}$} \\
\hline \multirow[t]{3}{*}{ Hispanic $(N=13,880)$} & Nonsmokers & & Reference & \\
\hline & Passive smokers & $1.70(1.25,2.31)$ & $1.08(0.91,1.29)$ & NA \\
\hline & Active smokers & $1.50(1.20,1.88)$ & $1.30(1.15,1.47)$ & $3.41(1.72,6.77)$ \\
\hline \multirow[t]{3}{*}{ Non-Hispanic Black $(N=11,434)$} & Nonsmokers & & Reference & \\
\hline & Passive smokers & $1.22(1.04,1.44)$ & $0.90(0.79,1.03)$ & $1.15(0.34,3.90)$ \\
\hline & Active smokers & $2.73(2.39,3.13)$ & $1.84(1.63,2.06)$ & $1.52(0.76,3.01)$ \\
\hline \multirow[t]{3}{*}{ Non-Hispanic White $(N=20,257)$} & Nonsmokers & & Reference & \\
\hline & Passive smokers & $1.21(0.76,1.93)$ & $1.05(0.87,1.26)$ & $0.94(0.60,1.47)$ \\
\hline & Active smokers & $2.91(2.37,3.57)$ & $1.64(1.49,1.80)$ & $0.97(0.76,1.22)$ \\
\hline \multirow[t]{3}{*}{ Other race $(\mathrm{N}=3767)$} & Nonsmokers & & Reference & \\
\hline & Passive smokers & $0.71(0.38,1.33)$ & $0.85(0.61,1.18)$ & $1.45(0.18,11.35)$ \\
\hline & Active smokers & $2.04(1.47,2.81)$ & $1.30(1.05,1.60)$ & $0.29(0.04,2.18)$ \\
\hline \multicolumn{5}{|l|}{$\mathbf{B M I}^{\mathrm{b}}$} \\
\hline \multirow[t]{3}{*}{$\operatorname{Normal}^{\mathrm{c}}(N=19,854)$} & Nonsmokers & & Reference & \\
\hline & Passive smokers & $1.23(0.99,1.53)$ & $0.89(0.77,1.02)$ & $1.04(0.61,1.76)$ \\
\hline & Active smokers & $2.47(2.11,2.90)$ & $1.59(1.44,1.76)$ & $1.20(0.91,1.59)$ \\
\hline \multirow[t]{3}{*}{ Overweight $(N=13,191)$} & Nonsmokers & & Reference & \\
\hline & Passive smokers & $1.25(0.93,1.68)$ & $0.96(0.80,1.16)$ & $1.24(0.59,2.61)$ \\
\hline & Active smokers & $1.98(1.66,2.37)$ & $1.46(1.31,1.63)$ & $0.86(0.57,1.31)$ \\
\hline \multirow[t]{3}{*}{ Obese $(N=16,293)$} & Nonsmokers & & Reference & \\
\hline & Passive smokers & $1.31(1.07,1.59)$ & $1.03(0.90,1.19)$ & $0.41(0.10,1.68)$ \\
\hline & Active smokers & $2.11(1.83,2.43)$ & $1.43(1.29,1.58)$ & $1.24(0.75,2.05)$ \\
\hline
\end{tabular}

${ }^{a}$ Estimates were adjusted for gender (categorical), age (continuous), BMI (categorical), PIR (continuous), and NHANES cycle (categorical). "NA" indicates that the analysis could not be derived due to limited cases

${ }^{\mathrm{b}}$ Estimates were adjusted for gender (categorical), age (continuous), ethnicity/race (categorical), PIR (continuous), and NHANES cycle (categorical)

${ }^{\mathrm{c}}$ Given that there were few cases $(1.7 \%)$ in the underweight category, underweight and normal weight were combined into one class in the regression analyses

nonsmokers (Kassi et al. 2015). In a cross-sectional study examining the association of smoking status with VD in 612 Chinese males aged 50 years and older, smokers also presented lower serum VD levels than nonsmokers (Jiang et al. 2016). Contrary to our positive relations found for tobacco smoke exposure with $25(\mathrm{OH}) \mathrm{D}$ concentrations in young participants aged 3-11-year and 12-19-year subgroups, a cross-sectional study carried out in Italy reported that passive smoking exposure in 152 children aged 5-15 years had lower levels of 25(OH)D (Chinellato et al. 2018). A Sweden cohort study based on 1068 males aged 18-20 years also indicated adverse effects of smoking on 25(OH)D levels (Lorentzon et al. 2007), whereas a nonsignificantly positive relation between smoking exposure and $25(\mathrm{OH}) \mathrm{D}$ was shown for pregnant women in an Iranian historical cohort (Banihosseini et al. 2013).

Evidence on the association between tobacco smoke exposure and VD status was rather limited, and there were no researches to date that estimated the effects of tobacco smoke on VD intoxication. Kassi et al. proved that young male smokers (20-29 years) had increased risk of VD deficiency (Kassi et al. 2015). An increased risk of VD inadequacy was also detected among Spanish smokers aged 18-84 years (Cutillas

-Marco et al. 2012). The NHANES 2001-2006 analyses demonstrated that American female active smokers aged $\geq 18$ years had higher prevalence of VD deficiency and inadequacy (Manavi et al. 2015). Although these epidemiological studies were limited to specific populations, their findings supported our results that tobacco smoke exposure, including active and passive smoking, was associated with increased risk of VD deficiency and inadequacy. It is noteworthy that the associations for smoke exposure with VD status were significant for participants with different races and BMI categories, indicating the adverse effects of exposure were stable. 
The mechanisms behind the disrupting effects of tobacco smoke on VD are unclear. On the ground of the foregoing experimental and epidemiological evidence, possible mechanisms for tobacco smoke exposure to interfere with VD were recently summarized as several highly likely pathways (Mousavi et al. 2019). First of all, smoking could induce skin aging, and smoking-derived aging may disturb the cutaneous production of VD. Second, dysfunctional VD-parathyroid hormones (PTH) axis due to tobacco smoke exposure could result in disruption of the VD metabolism. In addition, it appears that tobacco smoke is associated with dysregulation of enzymes genes related to the metabolism of VD. Another possible pathway is renal tubular dysfunction caused by tobacco smoke exposure. Heavy metals contained in tobacco may accumulate in kidneys, inhibiting VD activation through impairing kidney function. Besides, it is also hypothesized that tobacco smoke could depress intake of VD due to changed dietary taste. Although the exact explanation related to age difference is unknown, we assume that the observed protective effects of tobacco smoke exposure on VD levels in young people in our study might due to the very small numbers of exposed subjects. Nonetheless, further investigation is warranted to clearly ascertain mechanisms responsible for the reported smokingVD associations as well as age- and gender- differences.

Our study has multiple strengths. First, our study used a nationally representative sample with a large sample size, which allowed for exploring age- and gender-difference in the associations between tobacco smoke exposure and VD levels as well as potential modifying effects of several important factors. Second, the study provided important evidence for long-term trends in health impacts of tobacco smoke exposure over a 14-year period. Of note, smoking rates were consistently high over time, especially for active smoking among male adults and passive smoking among children. Moreover, protecting public health from tobacco smoke exposure could be made much more effective with understanding of this risk trend. Third, our study was the first to investigate effects of tobacco smoke exposure on VD intoxication, giving more clues on the disruptive role of tobacco smoke.

Our results, however, should be interpreted with caution due to following limitations. First, given the crosssectional nature of this study, no causal inference could be derived. Future evidence from prospective study design is warranted. Second, cotinine has a short half-life, and the measurement was based on a single spot serum sample. Therefore, the indicators detected could only represent a short-term level and the variation of individuals might be overlooked. In addition, the lack of data on sun exposure such as season and latitude, and dietary intake of VD in NHANES 2001-2006 hindered us from elaborating the possible biological mechanisms. However, after our further adjustment for dietary VD intake for participants with full dietary data in NHANES 2007-2014, significant associations between tobacco smoke and VD deficiency persisted. Also, although stratified analyses by age, gender, ethnicity/race, and BMI would help identify susceptible population, the multiple testing may also increase the chance of false positive findings. Thus, the current results from stratified analyses were exploratory.

In conclusion, the study indicated an increased trend for associations between tobacco smoke exposure and VD levels during 2001 to 2014. Serum cotinine was significantly and inversely associated with 25(OH)D in adult participants. Tobacco smoke exposure, including both active and passive smoking exposure, was associated with increased risk of VD deficiency in adults. Moreover, active smoking of adults was also related to increased risk of VD inadequacy. These associations showed somewhat gender difference, with consistent and stronger associations observed in female adults. In contrast, the effect of tobacco smoke exposure in children and adolescents aged 3-19 years on VD levels were mostly protective or non-significant. More researches are needed to verify our results.

Supplementary Information The online version contains supplementary material available at https://doi.org/10.1007/s11356-021-17905-5.

Acknowledgements We would like to thank all the NHANES participants and staffs for their time and effort over the years.

Author contribution Conception, methodology, writing, validation (Lei Yuan); Methodology, software, formal analysis, visualization (Jingyi $\mathrm{Ni}$ ). All authors read and approval the final manuscript.

Availability of data and materials The data underlying this article will be shared on reasonable request to the corresponding author. The datasets were derived from sources in the public domain: $\mathrm{CDC}, \mathrm{NCSH}$, and National Health and Nutrition Examination Survey, https://www.cdc. gov/nchs/nhanes/index.htm.

\section{Declarations}

Ethics approval and consent to participate The NCHS Research Ethics Review Board (ERB) approval and documented consent was obtained from all participants.

Consent for publication Not applicable.

Competing interest The authors declare no competing interests.

\section{References}

Ahmed Mohamed A, Salah Ahmed EM, Farag YMK, Bedair NI, Nassar NA, Ghanem AIM (2021) Dose-response association between vitamin D deficiency and atopic dermatitis in children, and effect modification by gender: a case-control study. J Dermatolog Treat 32(2):174-179. https://doi.org/10.1080/09546634.2019.1643447 
Akinkugbe AA, Moreno O, Brickhouse TH. Serum cotinine, vitamin D exposure levels and dental caries experience in U.S. adolescents. Community Dent Oral Epidemiol. 2019;47(2):185-192. factorshttps://doi.org/10.1111/cdoe.12442.

Banihosseini SZ, Baheiraei A, Shirzad N, Heshmat R, Mohsenifar A (2013) The effect of cigarette smoke exposure on vitamin D level and biochemical parameters of mothers and neonates. J Diabetes Metab Disord 12(1):19. https://doi.org/10.1186/ 2251-6581-12-19

Benowitz NL, Jacob P 3rd (1994) Metabolism of nicotine to cotinine studied by a dual stable isotope method. Clin Pharmacol Ther 56(5):483-493. https://doi.org/10.1038/clpt.1994.169

Benowitz NL (1996) Cotinine as a biomarker of environmental tobacco smoke exposure. Epidemiol Rev 18(2):188-204. https://doi.org/ 10.1093/oxfordjournals.epirev.a017925

Benowitz NL, Bernert JT, Caraballo RS, Holiday DB, Wang J (2009a) Optimal serum cotinine levels for distinguishing cigarette smokers and nonsmokers within different racial/ethnic groups in the United States between 1999 and 2004. Am J Epidemiol 169(2):236-248. https://doi.org/10.1093/aje/kwn301

Benowitz NL, Hukkanen J, Jacob P 3rd (2009b) Nicotine chemistry, metabolism, kinetics and biomarkers. Handb Exp Pharmacol 192:29-60. https://doi.org/10.1007/978-3-540-69248-5_2

Brot C, Jorgensen NR, Sorensen OH (1999) The influence of smoking on vitamin D status and calcium metabolism. Eur J Clin Nutr 53(12):920-926. https://doi.org/10.1038/sj.ejcn.1600870

Byun EJ, Heo J, Cho SH, Lee JD, Kim HS (2017) Suboptimal vitamin D status in Korean adolescents: a nationwide study on its prevalence, risk factors including cotinine-verified smoking status and association with atopic dermatitis and asthma. BMJ Open 7(7):e016409. https://doi.org/10.1136/bmjop en-2017-016409

CDC (2021) NCSH. National Health and Nutrition Examination Survey. https://www.cdc.gov/nchs/nhanes/about_nhanes.htm

Chatham-Stephens K, Law R, Taylor E, Melstrom P, Bunnell R, Wang B, Apelberg B, Schier JG; Centers for Disease Control and Prevention (CDC) (2014)Notes from the field: calls to poison centers for exposures to electronic cigarettes--United States, September 2010-February 2014. MMWR Morb Mortal Wkly Rep 63(13):292-3

Chinellato I, Piazza M, Sandri M, Paiola G, Tezza G, Boner AL (2018) Correlation between vitamin D serum levels and passive smoking exposure in children with asthma. Allergy Asthma Proc 39(3):814. https://doi.org/10.2500/aap.2018.39.4124

Cutillas-Marco E, Fuertes-Prosper A, Grant WB, Morales-SuárezVarela M (2012) Vitamin D deficiency in South Europe: effect of smoking and aging. Photodermatol Photoimmunol Photomed 28(3):159-161. https://doi.org/10.1111/j.1600-0781.2012. 00649.x

Jiang CQ, Chan YH, Xu L, Jin YL, Zhu T, Zhang WS, Cheng KK, Lam TH (2016) Smoking and serum vitamin D in older Chinese people: cross-sectional analysis based on the Guangzhou Biobank Cohort Study. BMJ Open 6(6):e010946. https://doi.org/10.1136/ bmjopen-2015-010946

Jorde R, Saleh F, Figenschau Y, Kamycheva E, Haug E, Sundsfjord J (2005) Serum parathyroid hormone (PTH) levels in smokers and non-smokers. The fifth Troms $\varnothing$ study. Eur J Endocrinol 152(1):39-45. https://doi.org/10.1530/eje.1.01816

Juonala M, Pitkänen N, Tolonen S, Laaksonen M, Sievänen H, Jokinen E, Laitinen T, Sabin MA, Hutri-Kähönen N, Lehtimäki T, Taittonen L, Jula A, Loo BM, Impivaara O, Kähönen M, Magnussen CG, Viikari JSA, Raitakari OT (2019) Childhood exposure to passive smoking and bone health in adulthood: the cardiovascular risk in young Finns study. J Clin Endocrinol Metab 104(6):24032411. https://doi.org/10.1210/jc.2018-02501

Kassi EN, Stavropoulos S, Kokkoris P, Galanos A, Moutsatsou P, Dimas C, Papatheodorou A, Zafeiris C, Lyritis G (2015) Smoking is a significant determinant of low serum vitamin $D$ in young and middle-aged healthy males. Hormones (athens) 14(2):245-250. https://doi.org/10.14310/horm.2002.1521

Lorentzon M, Mellström D, Haug E, Ohlsson C (2007) Smoking is associated with lower bone mineral density and reduced cortical thickness in young men. J Clin Endocrinol Metab 92(2):497-503. https://doi.org/10.1210/jc.2006-1294

Luo K, Liu J, Wang Y, Aimuzi R, Luo F, Ao J, Zhang J (2020) Associations between organophosphate esters and sex hormones among 6-19-year old children and adolescents in NHANES 2013-2014. Environ Int 136:105461. https://doi.org/10.1016/j.envint.2020. 105461

Mahamat-Saleh Y, Aune D, Schlesinger S (2020) 25-Hydroxyvitamin D status, vitamin D intake, and skin cancer risk: a systematic review and dose-response meta-analysis of prospective studies. Sci Rep 10(1):13151. https://doi.org/10.1038/ s41598-020-70078-y

Manavi KR, Alston-Mills BP, Thompson MP, Allen JC (2015) Effect of serum cotinine on vitamin D serum concentrations among american females with different ethnic backgrounds. Anticancer Res 35(2): $1211-1218$

Martuzevicius D, Prasauskas T, Setyan A, O’Connell G, Cahours X, Julien R, Colard S (2019) Characterization of the spatial and temporal dispersion differences between exhaled e-cigarette mist and cigarette smoke. Nicotine Tob Res 21(10):1371-1377. https://doi. org/10.1093/ntr/nty121

Marquina C, Mousa A, Scragg R, de Courten B (2019) Vitamin D and cardiometabolic disorders: a review of current evidence, genetic determinants and pathomechanisms. Obes Rev 20(2):262-277. https://doi.org/10.1111/obr.12793

Mitchell F (2020) Vitamin-D and COVID-19: do deficient risk a poorer outcome? Lancet Diabetes Endocrinol 8(7):570. https://doi.org/ 10.1016/S2213-8587(20)30183-2

Mousavi SE, Amini H, Heydarpour P, Amini Chermahini F, Godderis L (2019) Air pollution, environmental chemicals, and smoking may trigger vitamin D deficiency: Evidence and potential mechanisms. Environ Int 122:67-90. https://doi.org/10.1016/j.envint. 2018.11.052

NIDA. Tobacco, nicotine, and e-cigarettes research report. National Institute on Drug Abuse, 9 Jun. 2020, https://www.drugabuse. gov/publications/research-reports/tobacco-nicotine-e-cigarettes/

Nwosu BU, Kum-Nji P (2018) Tobacco smoke exposure is an independent predictor of vitamin D deficiency in US children. PLoS ONE 13(10):e0205342. https://doi.org/10.1371/journal.pone. 0205342

Pereira M, Dantas Damascena A, Galvão Azevedo LM, de Almeida Oliveira T, da Mota Santana J. Vitamin D deficiency aggravates COVID-19: systematic review and meta-analysis. Crit Rev Food Sci Nutr. 2020:1-9. https://doi.org/10.1080/10408398.2020.18410 90

Pott-Junior H, Nascimento CMC, Costa-Guarisco LP, Gomes GAO, Gramani-Say K, Orlandi FS, Gratão ACM, Orlandi AADS, Pavarini SCI, Vasilceac FA, Zazzetta MS, Cominetti MR (2020) Vitamin D deficient older adults are more prone to have metabolic syndrome, but not to a greater number of metabolic syndrome parameters. Nutrients 12(3):748. https://doi.org/10.3390/nu120 30748

Razzaque MS (2018) Can adverse effects of excessive vitamin D supplementation occur without developing hypervitaminosis D? J 
Steroid Biochem Mol Biol 180:81-86. https://doi.org/10.1016/j. jsbmb.2017.07.006

Sharief S, Jariwala S, Kumar J, Muntner P, Melamed ML (2011) Vitamin D levels and food and environmental allergies in the United States: results from the National Health and Nutrition Examination Survey 2005-2006. J Allergy Clin Immunol 127(5):11951202. https://doi.org/10.1016/j.jaci.2011.01.017

Soldin OP, Makambi KH, Soldin SJ, O’Mara DM (2011) Steroid hormone levels associated with passive and active smoking. Steroids 76(7):653-659. https://doi.org/10.1016/j.steroids.2011.02.042

\section{Authors and Affiliations}

\section{Lei Yuan ${ }^{1}$ (1) . Jingyi $\mathrm{Ni}^{1}$}

1 Clinical Research Center, Shanghai First Maternity and Infant Hospital, Tongji University School of Medicine, Shanghai, China
U.S. Department of Health and Human Services. Center for Disease Control and Prevention. Fourth National Report on Human Exposure to Environmental Chemicals Updated Tables, March 2021, Volume One. https://www.cdc.gov/exposurereport/index.html

Publisher's note Springer Nature remains neutral with regard to jurisdictional claims in published maps and institutional affiliations. 